\title{
Formação e capacitação de docentes para atuar com alunos com deficiência auditiva: um estudo no Instituto Federal do Espírito Santo - IFES
}

\author{
Wellington Gonçalves ${ }^{a}$ \\ Verana Maria Fornaciari Gonçalves b \\ Lilian Pittol Firme ${ }^{c}$
}

\section{Resumo}

Este trabalho apresenta um diagnóstico da formação e capacitação de docentes para atuar com alunos com deficiência auditiva. O estudo proposto tem por objetivo identificar a atual situação de formação e capacitação dos docentes do Instituto Federal do Espírito Santo (IFES) em relação a inclusão dos discentes com deficiência auditiva em sala de aula regular. Trata-se de um estudo de caso no qual os dados principais foram coletados junto aos docentes da instituição. O estudo proposto foi realizado em quatro campi do IFES. Os resultados indicaram a necessidade da realização de um planejamento pedagógico voltado à formação docente, no qual envolva o indivíduo, a família, o docente e a instituição. Ao realizar uma devolutiva em forma de relatório junto aos entrevistados e gestores dos campi, os resultados alcançados foram considerados satisfatórios, atingindo desta forma aos objetivos propostos. Adicionalmente, este trabalho deverá contribuir para a construção do conhecimento no que tange à inclusão de pessoas com deficiência auditiva. Os resultados podem ser adaptados à realidade de diferentes situações, regiões e localidades que identificarem a necessidade de capacitação docente, tendo como visão a inclusão de alunos com deficiência auditiva, respeitando os princípios dos pilares éticos, sociais e normativos de cada realidade. Sendo necessário que a escola encontre alternativas práticas, construídas e dialogadas para incluir efetivamente.

Palavras-chave: Inclusão escolar. Formação e capacitação docente. Deficiência auditiva.

\footnotetext{
a Universidade Federal do Espírito Santo - UFES. Vitória, Espírito Santo, Brasil.

b Instituto Federal de Educação, Ciência e Tecnologia do Espírito Santo - IFES. Vitória, Espírito Santo, Brasil.

c Faculdade Vale do Cricaré - FVC. São Mateus, Espírito Santo, Brasil.
} 


\section{Introdução}

Historicamente as pessoas com deficiência eram tratadas como beneficiários passivos de apoio, com base em sentimentos de piedade (LAMICHHANE; SAWADA, 2013). Durante o movimento pelos direitos civis, por volta dos anos 1960 e 1970, os Estados Unidos da América introduziram uma variedade de estratégias e programas, visando fomentar uma mudança das políticas sociais, que, até então, eram baseadas na exclusão (COOK; BURKE, 2002).

No Brasil, ao reconhecer os direitos das pessoas com deficiência em seu Art. 201, a Constituição Federal de 1988 representa um importante marco judiciário sobre a política nacional relacionada às pessoas com deficiência (BRASIL, 1988), abrindo caminhos para novas legislações a respeito do tema. Como a Lei ${ }^{\circ} 7.853 / 89$ disciplinada pelo Decreto ${ }^{\circ} 3.298$, de 20 de dezembro de 1999, a chamada "Lei de Cotas", que instituiu a reserva de mercado de trabalho, balizando a política nacional para integração da pessoa com deficiência, com a criação de normas e condutas para acessibilidade (BRASIL, 1999). Na atual conjuntura, o Brasil vivencia uma etapa de efervescência dos movimentos sociais que demandam usufruto de direitos conquistados, mas, nem sempre, respeitados (FRANÇA; PAGLIUCA; BAPTISTA, 2008).

Vale ainda ressaltar, no cenário brasileiro, quase $1 / 4$ da população (23,9\%) apresenta algum tipo de deficiência, o que significa cerca de 45,6 milhões de pessoas, o censo demográfico na avaliação por tipo, mostrou que 9.717 .318 pessoas apresentam algum grau de deficiência auditiva (IBGE, 2010). O significante volume de pessoas com algum tipo de deficiência indica a necessidade da ampliação do conhecimento sobre as condicionantes, que podem auxiliar na melhora da qualidade da formação acadêmica dessas pessoas.

Nesse contexto, Kunze (2009) cita que as escolas técnicas possuem raízes históricas associadas à inclusão, sendo relacionada tanto ao desenvolvimento tecnológico, quanto à promoção do nível acadêmico brasileiro. Com isso, além de estarem fomentando a construção de um saber técnico, as escolas técnicas também possuem a missão da inclusão social, o que pode ser visto como importante aliado na construção do saber.

A ascensão da inserção escolar de pessoas com deficiência impulsiona os profissionais da educação a conhecerem as formas e maneiras de aprender dessas pessoas e, com isso, as próprias limitações e possibilidades de aprendizado, pois cada aluno possui suas particularidades e tempo de aprendizado diferente (COSTA et al., 2013), a inserção do discente com insuficiência ou limitações 
representa um desafio a ser transposto, em todas as modalidades de ensino, tanto nas instituições públicas, como nas privadas.

O princípio da inclusão que, cada vez mais, se estabelece na sociedade é fundamental para que os alunos não sejam apenas aceitos nas escolas, mas que estas lhes assegurem sua permanência, e sua efetiva participação nas aulas e demais atividades escolares, objetivando o seu desenvolvimento (MIOTTO, 2010). A evidência está na mudança da educação comum, na adequação, nas percepções e nas práticas pedagógicas tradicionais, suprimindo, desta forma, os impedimentos que limitam o aprendizado dos discentes.

Lima e Castro (2012), destacam que privar qualquer pessoa de conhecer e buscar conhecimento é impedir o seu crescimento e a sua formação. Essas restrições podem ocorrer pela falta de conhecimento das variáveis que influenciam e limitam o aprendizado dos alunos com deficiência auditiva.

E com isso, tem sido reiterada a necessidade do alinhamento de saberes, em que passa ser necessário o compartilhamento de informações e conhecimentos para a construção do saber ensinar, preparando, assim, os educadores para atuarem na inclusão de alunos com deficiência, e na medida em que essa inserção acontece, um ensino adaptado às diferenças e às necessidades individuais passa a ser necessário (MICHELS, 2011; FAGLIARI, 2012). Neste sentido, os docentes precisam estar habilitados e devidamente capacitados para exercerem sua função de forma competente junto aos alunos inseridos nos vários níveis de ensino (AZAMBUJA; SOUZA; PAVÃO, 2012).

No campo da educação especial, o diálogo entre a psicopedagogia, sistemas de avaliação pedagógica e as metodologias e lógicas classificatórias é intenso, contudo, nem sempre suficientemente elucidado. Embora a intenção deste trabalho seja identificar a atual situação de formação e capacitação dos docentes do Instituto Federal do Espírito Santo (IFES) em relação à inclusão dos discentes com deficiência auditiva em sala de aula regular, também temos o intuito de indicar possíveis caminhos para a criação de novas formas de leitura, reconhecimento e valorização da diversidade humana, que tanto têm sido demarcadas pela radicalidade histórica de nossas concepções.

Para tanto, como a hermenêutica filosófica do ensino nos oferece os fios que tecem a construção do saber e das possibilidades do compreender e interpretar, assim, as discussões que serão apresentadas nos propõem pensamentos e questionamentos que, nem sempre, possuem respostas prontas e definitivas. Consequentemente, não 
é nossa intenção esgotar o assunto, nem mesmo garantir respostas decisivas a todos os temas, mas buscar reflexões a respeito dos questionamentos formulados. Isto porque adotamos a ideia de que nossa sociedade é mutável, e estando as ansiedades e necessidades humanas inseridas neste contexto, as práticas pedagógicas devem estar sempre em constante transformação.

\section{Pessoa com Deficiência Auditiva}

Campos, Silveira e Santarosa (1999) definem pessoa com deficiência auditiva, aquele indivíduo que possui perda total ou parcial da audição. Nesse contexto, Piatto e Maniglia (2001), afirmam que a Organização Mundial de Saúde (OMS) utiliza os termos deficiência auditiva e hipoacusia como sinônimos para determinar uma dificuldade em ouvir, porém, sem prejuízos na comunicação.

No Brasil, as pesquisas demográficas, desde o ano de 1872, incluem informações sobre deficiência, e estas pesquisas refletiam a visão de que deficiência se define por um conjunto específico de defeitos corporais (IBGE, 2010). Contudo, a partir do Decreto da Presidência da República n 3.298, de 1999, o termo deficiência começou a aparecer com maior ênfase no território brasileiro, passando a ser entendido como a perda ou anormalidade de uma estrutura ou função psicológica, fisiológica ou anatômica, que gere incapacidade para o desempenho de atividade, dentro do padrão considerado normal para o ser humano (BRASIL, 1999).

O Decreto ${ }^{\circ} 5.296 / 2004$, define que deficiência auditiva é a perda bilateral, parcial ou total, de quarenta e um decibéis $(\mathrm{dB})$, ou mais, aferida por audiograma nas frequências de $500 \mathrm{~Hz}, 1.000 \mathrm{~Hz}, 2.000 \mathrm{~Hz}$ e $3.000 \mathrm{~Hz}$ (BRASIL, 2004). Entretanto, anteriormente à publicação deste Decreto, não havia um reconhecimento claro quanto à existência da diversidade entre pessoas com deficiências semelhantes.

No campo da deficiência auditiva, o discernimento social é por vezes variado e confuso, e o indivíduo que apresenta essa condição é sempre visto de forma deficitária, por uma coletividade que ergue seus valores e suas práticas pensando na cultura sonora, em que o ouvir bem é necessário (SILVA; ARAÚJO, 2012). Segundo estes autores, este tipo de prática tem sido levada para o ambiente de aprendizagem, em muitas vezes, dificultando e limitando a captação e percepção do indivíduo.

Para Seno (2009), o sucesso do processo de inclusão de pessoas com deficiência auditiva está associado à possibilidade de reconhecer diferenças e aceitá-las dentro e fora do processo de aprendizagem. Isso não significa ignorá-las, pois, de acordo 
com este autor, colocar indivíduos com necessidades educacionais especiais em um ambiente e esperar que eles aprendam pela proximidade com seus colegas da mesma idade, é algo que tende a proporcionar resultados insatisfatórios. Nesse sentido, respeitar e aceitar as diferenças pode ser entendido como o início das ações para oportunizar os demais recursos necessários para o desenvolvimento da aprendizagem do indivíduo.

O processo de ensino e aprendizagem de indivíduos com necessidades especiais se baseia em três elementos fundamentais: o próprio sujeito, o professor e a família; e quando nos referimos à educação, esse conjunto se torna essencial para a formulação de estratégias pedagógicas e o desenvolvimento de conteúdo (SILVA; FÉLIX; JORGE, 2014). Dentro desse contexto, estes autores ainda destacam que o docente deve estar capacitado de forma a conseguir trabalhar as dificuldades do educando, sendo a família um elemento imprescindível dentro desse processo, devendo ambos se adequarem às necessidades do indivíduo.

A deficiência auditiva pode causar diversos impactos na vida das pessoas que a possuem, e dentre eles pode ser destacado a incapacidade de relacionamento social, pois, na maioria dos casos, a linguagem falada não é desenvolvida. Se uma pessoa jovem ou adulta não tiver a oportunidade de aprender a linguagem de sinais enquanto criança, esta poderá ter acesso limitado a serviços e ao convívio social, gerando um impacto emocional, causando sentimentos de solidão, isolamento e frustração (WHO, 2014).

Com isso, as orientações dos profissionais da educação devem ser cautelosas e claras, a fim de evitar insegurança, ansiedade, expectativas irreais ou reações inadequadas dos pais, que podem ser mais prejudiciais do que a deficiência em si. Holzheim et al. (1997) citam que ouvir os pais e permitir que expressem seus pensamentos pode ser mais uma alternativa na busca pela construção do conhecimento das pessoas com deficiência auditiva.

Para Sassaki (2003), nunca existiu ou existirá somente um termo adequado e definitivo a ser utilizado em todos os ambientes, pois em cada época são utilizados termos que possuem significados adaptáveis com os valores atuais de cada sociedade. Logo, a opção de emprego da terminologia "pessoas com deficiência" neste trabalho, pode ser atribuída ao fato de que é uma nomenclatura proposta pela legislação vigente, e também pela contribuição de pessoas com deficiência na elaboração do tratado de Direitos Humanos (MAZZOTTA; D'ANTINO, 2011). 
Diante deste cenário, que tem permeado ao longo do tempo, definições diferentes sobre deficiência, a inclusão tem sido uma preocupação frequente, inclusive por parte das instituições de ensino, principalmente devido à legislação como a Lei de Diretrizes e Bases da Educação Nacional (LDB), na qual a educação especial é enfatizada como prioritária para as pessoas com deficiência (BRASIL, 1996).

\section{Legislação brasileira para inclusão}

A origem da legislação brasileira para inclusão relaciona-se com a necessidade de atendimento às pessoas com deficiência na época do Império, em que foram criadas duas instituições: o Imperial Instituto dos Meninos Cegos, em 1854, atual Instituto Benjamin Constant (IBC), e o Instituto dos Surdos-Mudos, em 1857, hoje denominado Instituto Nacional da Educação dos Surdos (INES), ambos no Rio de Janeiro (BRASIL, 2008a). A criação destas instituições demandou a elaboração de uma legislação específica, que até então não era assistida pelo governo.

$\mathrm{O}$ atendimento educacional às pessoas com deficiência sobreveio pelas disposições da LDB, Lei no 4.024/1961 (BRASIL, 1961), que apontava o direito de todos à educação, tendo uma preferência para que acontecesse na rede regular de ensino, porém, a legislação não apontava com clareza o papel, funções, atividades e ações a serem realizadas, somente fixava que cada estabelecimento, público ou particular, deveria organizar-se por meio de regimento próprio.

Em 1973, o Centro Nacional de Educação Especial (CENESP), foi criado pelo Ministério da Educação (MEC) com a responsabilidade de gerenciar a educação especial no Brasil (BRASIL, 2008b). Este órgão foi ainda responsável por implantar um padrão de política pública, amparado na produção de bibliografias impressas, com o objetivo da formação em serviço, divulgação dos princípios norteadores da organização e funcionamento da Educação Especial no Brasil (BRASIL, 1995).

A Lei $n^{\circ} 8.069 / 1990$, mais conhecida como o Estatuto da Criança e do Adolescente (ECA), nos seus artigos $1^{\circ}, 3^{\circ}$ e $4^{\circ}$ destaca a importância da atenção às pessoas com deficiência, apontando ser um dever de todos, para o alcance deste objetivo (BRASIL, 1990).

Nesse mesmo contexto, a Declaração de Salamanca previa que as pessoas com deficiência devam ter acesso às escolas comuns, e que estas têm a obrigação de incluí-las por meio de uma pedagogia centralizada na criança, capazes de atender às suas necessidades (UNESCO, 1994). Esse documento proclama a escola para todos ou escola inclusiva, defendendo o direito inalienável de crianças 
e jovens com deficiência terem acesso às escolas regulares, como também, a necessidade de escolas e professores se adequarem e serem capazes de atender a essas necessidades (ALMEIDA; ROCHA; PEIXOTO, 2013).

A Lei $n^{\circ}$ 9.394/1996 que estabelece as diretrizes e bases da educação nacional (BRASIL, 1996), dispõe em seu capítulo V que a educação de pessoas com deficiência deve se dar, preferencialmente, na rede regular de ensino, esta legislação pode ser considerada como precursora da ressignificação da política da educação especial. Entretanto, o fato de constar na legislação a priorização das pessoas com deficiência, não é suficiente para a inclusão, tendo em vista a forma não planejada em que as escolas regulares ofertam o atendimento e ensino a estas pessoas (SANTOS; PEREIRA; LIMA, 2014).

A Lei $\mathrm{n}^{\circ}$ 10.436/2002 oficializou a Libras (Língua brasileira de sinais) no Brasil, como meio legal de comunicação e expressão, tornando uma disciplina curricular obrigatória nos cursos de Formação de Professores para o exercício do magistério, em nível médio (antigo curso normal) e superior, nos cursos de Pedagogia, Educação Especial, Fonoaudiologia e Letras (BRASIL, 2002). Libras é uma língua usada por pessoas com deficiência auditiva no Brasil, tendo todos os elementos estruturais e gramaticais que compõem uma língua (XAVIER; BARBOSA, 2013).

Em 2008, com a publicação do documento a Política Nacional de Educação Especial na Perspectiva da Educação Inclusiva - PNEE-EI (BRASIL, 2008b), houve início de um processo de renovação da política da educação especial. Fagliari (2012), comenta que a educação especial, nesse documento, articula-se com o ensino regular, integrando a proposta pedagógica da escola, com vistas a promover $\mathrm{o}$ atendimento das necessidades educacionais dos alunos com deficiência.

Contudo, a partir da Lei no 12.796/2013 (BRASIL, 2013), houve alterações das definições e conceitos na educação especial, sendo esta reorganizada sob uma perspectiva de educação inclusiva, tendo como um de seus princípios a ampliação do atendimento ao educando com deficiência.

\section{Inclusão escolar: formação docente em geral (competências e habilidades) e a formação de pessoas com deficiência auditiva}

Nas últimas décadas, incluir alunos com deficiência no sistema regular de ensino tem sido uma das questões mais discutidas no Brasil, devido ao amparo e fomento pela aplicação da legislação. No entanto, neste contexto, destaca-se o despreparo 
dos professores para receber nas salas de aula das escolas regulares alunos com deficiência, como mostrado nos resultados das pesquisas de Naujorks (2002), Santos (2007), Siems (2008) e Rodrigues (2008).

Diante disso, a inclusão surge pela urgência de responder às necessidades das pessoas com deficiência, nomeadamente, na sua inclusão na vida em sociedade. Desta forma, a escola inclusiva, segundo a literatura, passa a valorizar todo o sistema educativo baseado na diferenciação curricular, reorganizando os contextos (MENDES; OLIVEIRA; NAZÁRIO, 2008; TREVISAN; DELLABARBA, 2012; SILVA, 2013).

A partir desses argumentos, na atualidade, segundo Smeha e Ferreira (2008), muito se tem discutido sobre o conceito de competência, por ainda apresentar-se como um enigma para os educadores, que pode, muitas vezes, ser um fator de desestímulo profissional.

As competências são conhecimentos essenciais para que a compreensão das questões relativas à formação e à prática do professor, já inseridas nas instituições de ensino, seja o ponto de partida para a formação das pessoas com deficiência (AZAMBUJA; SOUZA; PAVÃO, 2012). Porém, estes autores ainda destacam serem necessárias habilidades intrínsecas a cada caso, para lidar com o dia-a-dia junto aos discentes.

Segundo Perrenoud (2000), competência pode ser entendida como a faculdade de movimentar um conjunto de recursos cognitivos compreendendo saberes, capacidades, informações, entre outros, para solucionar, com conveniência e eficácia, uma série de situações pedagógicas. Alberti et al. (2014), descrevem competência como sendo a articulação de conhecimentos, habilidades e valores/atitudes voltados para o aprendizado e formação discente.

Considerando a aprendizagem na educação profissional, de acordo com Pereira (2013), ela se integra ao aprender a aprender, aprender a fazer, aprender a conviver e aprender a ser, saberes que garantem o desenvolvimento de competências, e, nessa perspectiva, a metodologia de ensino não demanda meramente o uso do vídeo, do trabalho em grupo, da aula expositiva, dentre outros recursos pedagógicos, é necessário que a sala de aula realize-se em uma aproximação entre a teoria e a prática por meio da contextualização, em uma abordagem interdisciplinar.

Embora haja diversas enunciações sobre o conceito de competências com diferentes componentes, de maneira geral, todos envolvem o saber-saber, saber-fazer e 
saber-ser (BEHAR; TORREZZAN, 2014). Definir competência unicamente por meio de cada um destes componentes gerais, pode ser, no entanto, uma limitação ao aprendizado, uma vez que os saberes fazem parte da competência, mas não se podem confundir com ela, e as competências são caracterizadas como ações, mas não é o fato de descrever as ações que explica ou que possibilita a ação, ou o seu êxito (DIAS, 2010).

Contudo, novas áreas de competência docente têm surgido, por exemplo, o uso de métodos ativos e expressivos que valorizem e incentivem a investigação dos alunos, que podem servir de ferramenta motivacional, e com isso, os professores são chamados a serem proficientes no trabalho com grupos, e no uso de estratégias interativas (RODRIGUES; LIMA-RODRIGUES, 2011).

Nesse sentido, as capacidades dos docentes podem contribuir para a elevação do nível de consciência dos educandos e, consequentemente, à autonomia do fazer docente (COSTA, 2013). Essas capacidades podem ser obtidas por meio de ações político-pedagógicas implementadas pelos professores, que, por sua vez, tendem a contribuir para a afirmação da educação democrática e inclusiva, servindo de vetor para contrariar a segregação e à exclusão tanto na escola, quanto nas demais instâncias sociais.

A formação inadequada ou com uma competência, de forma geral, comprometida, pode proporcionar chances de influências negativas junto aos educandos (SALA, 1993). Na Política Nacional de Educação Especial na Perspectiva da Educação Inclusiva, a formação dos professores pode se dar por intermédio da formação continuada (BRASIL, 2008b) e, com isso, almeja-se minimizar os impactos da falta de formação.

Contudo, além de manter ambiguidades, a proposição atual de formação docente não rompe com o modelo de formação tradicionalmente destinado à área (MICHELS, 2011) e, desta forma, essa concepção pode levar os educandos a terem percepções distorcidas sobre o ensino inclusivo.

As ações dos docentes decorrem de um longo processo iniciado na família, perpassado pelas demais inserções até chegar às atividades desenvolvidas no interior da escola, em um processo de socialização/formação contínua (MARIN; ZEPPONE, 2012). Nesse contexto, ao longo desse percurso, a formação das pessoas com deficiência recebe múltiplas interferências e, desta forma, levam todos os atores a alterarem suas posturas dentro do processo de ensino-aprendizagem. 
Embora tenham ocorrido conquistas e avanços, a educação de pessoa com deficiência auditiva no Brasil corre o risco de manter as práticas excludentes do passado (THOMA; KLEIN, 2010). A formação desses discentes, segundo os autores, pode ficar comprometida, gerando profissionais com sua empregabilidade negativamente afetada.

\section{Estudo do processo inclusivo no IFES}

Devido ao fato do IFES ser uma instituição federal vinculada ao MEC, fundada em 1909, que oferta cursos técnicos integrados ao Ensino Médio, cursos técnicos concomitantes e subsequentes, cursos de graduação, pós-graduação e especializações (IFES, 2014), e por estar em um momento de expansão de cursos e estruturas físicas, esta instituição foi selecionada para realização deste estudo.

Atualmente o IFES possui 19 campi (Figura) distribuídos pelo Estado do Espírito Santo, assim, por uma questão de proximidade e estarem em uma área de acessibilidade dos pesquisadores, os campi Aracruz, Linhares, São Mateus e Nova Venécia foram selecionados como universo da pesquisa, possuindo um conjunto de 220 docentes (efetivos e contratados).

A inquietação com o processo de construção do saber e da autonomia da escola, que se constitui, ainda como um discurso (ALARCÃO, 2010), motivou esta pesquisa. Diante disso, empreendemos um estudo para buscarmos auxiliar esse processo, tendo a inclusão de pessoas com deficiência auditiva como objeto de pesquisa. Assim, por envolver a investigação baseada na prática e experiência de especialistas, podendo ser utilizado de modo exploratório para investigar fenômenos, o método estudo de caso foi selecionado para ser adotado neste trabalho como estratégia investigativa de pesquisa (ANDRÉ, 2013).

Em se tratando do método estudo de caso, Alves (1991) e Yin (2015) destacam que a definição da população e amostra deve ser criteriosa, permitindo a visualização do fenômeno investigado. Este tipo de abordagem, segundo estes autores, ressalta a importância da seleção de uma amostragem significativa e representativa da população, que pode proporcionar uma visão temporal das variáveis em estudo.

Os dados foram coletados não exclusivamente para uma análise sobre o processo de inclusão dos alunos com deficiência auditiva, mas também para demonstrar a importância do conhecimento diagnosticado na pesquisa para o planejamento de futuras ações que busquem abordar tal temática, além de buscar informações para investigação de um caso específico, visualizado por diferentes olhares, sendo relatado por diversas opiniões. 
Desta forma, além de envolver um levantamento bibliográfico inicial para entendimento da temática pesquisada, foram realizadas entrevistas com docentes sobre experiências práticas com o problema estudado, no período compreendido entre 2014.1 e 2014.2, por meio de um questionário on-line. Frente aos aspectos apontados ao longo do texto, no que tange à identificação e estudo da formação e capacitação de docentes para atuar com alunos com deficiência auditiva, no instrumento de coleta de dados, coube considerar os riscos de um remonte aos aspectos da formação acadêmica inadequada, má ou ausente, face aos tensionamentos vividos no âmbito das escolas técnicas, visando à obtenção de um diagnóstico que identifique os sujeitos da educação especial e defina seu percurso escolar.

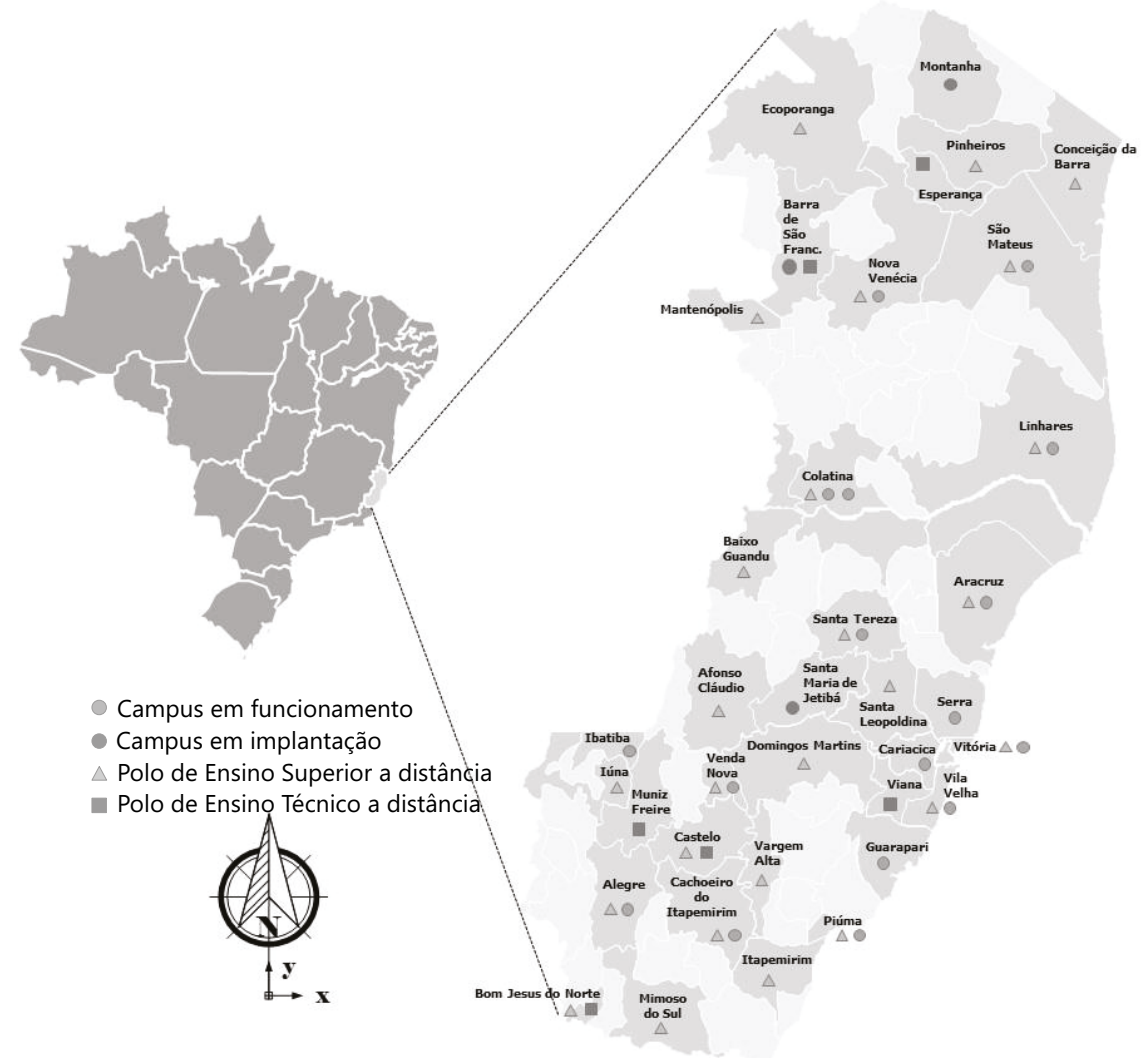

Fonte: IFES (2014).

Figura. Distribuição dos campi do IFES. 
A partir desta ação, foi realizada a aplicação do questionário on-line a uma amostra de $2 \%$ do universo da pesquisa (4 docentes), selecionada aleatoriamente, sob a forma de pré-teste. Com isso, foi verificada a aderência do questionário ao cenário, experiências e realidades vivenciadas pelos docentes, desta forma, foram obtidas sugestões e informações quanto à compreensão e entendimento deste instrumento. Na sequência, foi realizada outra testagem em uma amostra de $10 \%$ do universo da pesquisa ( 22 docentes), selecionada aleatoriamente, sendo observada a compreensão dos respondentes a respeito das adaptações realizadas a partir do pré-teste. Por fim, ao enviar a versão final do questionário, foram recebidas 203 respostas, no entanto, 18 formulários, com mais de $10 \%$ de dados ausentes, foram excluídos e, com isso, o tamanho da amostra remanescente foi composto por 185 docentes, podendo ser considerado significativo por representar $84,09 \%$ do universo da pesquisa. A análise dos dados foi realizada com auxílio de uma planilha eletrônica, a partir da consideração dessa significância com relação à representatividade da amostra.

Como perfil geral, a amostra indicou que $74 \%$ dos respondentes estão na faixa etária entre 20 a 40 anos, com $95,6 \%$ possuindo formação acadêmica entre mestres, especialistas e graduados. Contudo, uma repetição da formação docente que tem prevalecido na educação tecnológica no Brasil pode ser observada (CARVALHO; SOUZA, 2014) ou seja, $81 \%$ possuem graduação em engenharias ou ciências exatas e da terra, e não têm qualquer formação voltada ao ensino, assinalando, com isso, a necessidade de discussão considerando as práticas pedagógicas reincidentes, visto que, no cotidiano, as dificuldades das pessoas com deficiência auditiva exigem conhecimento técnico e uma prática aplicada a cada caso.

Assim, quando no contexto de uma instituição de ensino pertencente a uma rede, que já possui histórico e tradição no ensino tecnológico, o trabalho pedagógico com alunos com deficiência auditiva, exige uma identificação e cuidados além dos padrões adotados. Nesse sentido, cabem ressalvas e análises sobre como esta concepção vem acontecendo, bem como, quais as bases teóricas e conceituais têm amparado os métodos de caracterização destes sujeitos, quiçá pautados nas dimensões pedagógicas e escolares para pessoas com deficiência auditiva. Desta forma, analisando o tempo em que os docentes pesquisados lecionam em cursos técnicos, pode-se verificar que $76,6 \%$ dos respondentes possuem até 10 anos de experiência em ensino, entretanto, $68,4 \%$ não possuem experiência com pessoas com deficiência auditiva, sejam discentes ou não, destacando a ausência de vivência e consequente falta de conhecimento tácito. 
Cabe ressaltar que os cursos de formação de professores para o atendimento educacional especializado não têm inserido na sua formação e no seu material didático a discussão sobre os processos diagnósticos e de identificação dos sujeitos no ambiente escolar, assim como, a indicação de procedimentos e métodos para o lidar no cotidiano, como se tais informações já estivessem definidas a priori, não considerando a complexidade e características deste fenômeno. Uma questão importante nesse contexto é o fato de $89,2 \%$ dos respondentes não terem realizado, nos últimos 5 anos, qualquer atividade de formação ou capacitação, para atuarem com pessoas com deficiência auditiva, sejam discentes ou não.

No entanto, embora em sua maioria os docentes tenham experiência em ensino, lacunas em sua formação têm sido percebidas, e, segundo os respondentes, isso tem refletido em seu desempenho, devido à ausência de competências e habilidades necessárias às funções acadêmicas. Assim, a formação pedagógica e psicopedagógica se destaca com $69,9 \%$ das respostas, sendo apontada como uma necessidade prioritária no cotidiano da instituição, seguida da parceria entre profissional de ensino regular e profissionais de educação especial, com 23,7\%, na qual experiências práticas podem ser compartilhadas, as quais podem permitir uma percepção por meio de casos práticos, e a concepção atitudinal com $6,4 \%$, na qual os respondentes concordam sobre a necessidade de mudança de postura, tanto com relação aos instrumentos pedagógicos utilizados em sala de aula, como na visualização de possíveis limitações de aprendizado.

Para os docentes, cada ambiente de aprendizagem necessita de uma abordagem de ensino quando o aluno possui uma deficiência ou limitação. Com isso, a necessidade da realização de palestras $(75,6 \%)$, workshops $(18,1 \%)$ e seminários $(6,3 \%)$ foram apontadas como possíveis soluções na ampliação de horizontes, as quais podem fornecer novas ideias para implementação de estratégias didáticopedagógicas a serem desenvolvidas para atuação em sala de aula junto às pessoas com deficiência auditiva.

Uma devolutiva dos resultados obtidos foi realizada junto aos entrevistados, por meio de relatório eletrônico, contendo todos os dados, informações, comentários e um questionário voltado à verificação da validade destes conhecimentos gerados, tendo por finalidade atestar a aplicabilidade e funcionalidade da proposta deste estudo às realidades vivenciadas em seu cotidiano, além de verificar o interesse dos docentes em avaliar suas condições para atuarem com pessoas com deficiência auditiva. Assim, foram recebidas 172 respostas, no entanto, 13 formulários com mais de $10 \%$ de dados ausentes foram excluídos e, com isso, o quantitativo 
final foi de 159 respostas. Esse universo pode ser considerado significativo por representar $85,94 \%$ do universo da pesquisa.

Não foram observadas divergências com relação ao relatório sobre o diagnóstico realizado, sendo atestada a validade de todas as informações obtidas. No entanto, foi ressaltada a necessidade da realização de uma avaliação individual, objetivando realizar um mapeamento das competências e habilidades individuais que devem ser trabalhadas junto aos docentes, a fim de proporcionar melhores condições para a inclusão de pessoas com deficiência auditiva no IFES.

É importante destacar que as respostas do diagnóstico desenvolvido neste trabalho, embora representem condições e preferências atuais dos docentes para atuarem com pessoas com deficiência auditiva, devem ser consideradas como uma decisão prescritiva, e não normativa, ou seja, em outra aplicação futura, os especialistas possuem liberdade para revisar, ou decidir contrariamente as respostas aqui apresentadas. E, desta forma, para melhor aplicação deste diagnóstico, se faz necessário uma análise prévia sobre a realidade em que será aplicado o mesmo.

\section{Considerações Finais}

Desta forma, baseando-se nas informações coletadas neste estudo, é eminente a necessidade de implantação de um programa de capacitação de docentes para inclusão de alunos com deficiência auditiva, baseado nas visões, vivências, experiências, expectativas e ansiedades dos docentes, podendo este ocasionar melhores resultados nas práticas atuais do IFES, levando-se em consideração um planejamento prévio das ações a serem implementadas.

Ao realizar devolutiva junto aos entrevistados e gestores dos campi, os resultados obtidos foram considerados satisfatórios por sua abrangência, sendo destacado que a contribuição deste trabalho alavancará novos planejamentos e ações para a capacitação de docentes. Assim, considerando as proposições iniciais deste trabalho, mediante os resultados alcançados e da validação junto aos entrevistados, pode-se afirmar que os objetivos propostos foram atingidos.

Tendo em vista os resultados obtidos e as discussões apresentadas sugere-se, a seguir, alguns temas para a realização de trabalhos futuros, que possam contribuir para complementar ou expandir esta pesquisa: a ampliação do campo de pesquisa para todos os campi, podendo com isso, analisar as possíveis particularidades e necessidades de cada região, e o mapeamento e estudo sobre alternativas para 
formação e capacitação de docentes visando a inclusão de alunos com deficiência auditiva no processo de ensino-aprendizagem.

As questões levantadas ao longo do texto nos levam a pensar sobre a educação especial como uma área do conhecimento que se torna possível alcançar, graças ao arranjo de saberes médicos, psicológicos e pedagógicos. Na literatura, parece evidente, no contexto de fragmentos discursivos, a atenção e valor dados ao diagnóstico como agente de identificação, caracterização e descrição das ansiedades e expectativas das pessoas com deficiência auditiva.

Poderíamos avançar mais, entretanto, esta não é uma discussão a ser alcançada por três pesquisadores, buscamos colaboradores para nos auxiliar a pensar nas questões que dinamizaram este texto: Como o discurso da avaliação pedagógica tem substituído, ou tornado rarefeito o discurso sobre a realização do diagnóstico da formação e capacitação de docentes, já que é colocado em segundo plano? Quais as causas que promovem as condições para que este discurso da avaliação substitua o de diagnóstico? Como e por que o discurso da avaliação se apresenta com legitimidade e fixa suas fronteiras?

Logo, refletindo sobre estes argumentos de discussão, não podemos abrir mão de problematizar estas questões, pois elas estão indicando e diferenciando um modo de atuar e pensar do professor nos últimos anos e, com isso, determinando por si as dimensões do saber da educação especial e da escola inclusiva, assim, este docente pode estar validando o lado pedagógico da avaliação, e apagando inconscientemente aquilo que ela possui de diagnóstica. 


\title{
Training of teachers for working with students with hearing impairment: $a$ study at the Federal Institute of Espírito Santo - IFES
}

\begin{abstract}
This paper presents an analysis of the training of teachers for working with students with hearing impairment. The proposed study aims to identify the current situation of education and training of the IFES teachers regarding the inclusion of hearing impaired students in regular classrooms. It is a case study in which the main data were collected from the teachers of the institution. The proposed study was conducted in four campuses of IFES. The results indicated the need to carry out an educational plan aimed at teacher training, involving the individual, the family, the teachers and the institution. When performing a feedback in the form of report with the interviewees and managers from the campuses, the results were considered as satisfactory, accomplishing the proposed objectives. In addition, this work should contribute to the construction of knowledge regarding the inclusion of people with hearing impairment. Results can be adapted to the reality of different situations, regions and localities to identify the need for teacher training, with the aim to include students with hearing impairment, respecting the principles of ethical, social and normative pillars of each reality. It is necessary that the school finds alternative practices, built and dialogued to effectively include.
\end{abstract}

Keywords: School inclusion. Teacher education and training. Hearing impairment. 


\section{Formación y capacitación de docentes para trabajar con estudiantes con discapacidad auditiva: un estudio en el Instituto Federal de Espírito Santo - IFES}

\section{Resumen}

En este trabajo se presenta un análisis de la formación de maestros para trabajar con estudiantes con discapacidad auditiva. El estudio propuesto tiene como objetivo identificar la situación actual de la educación y la formación de los maestros del IFES con respecto a la inclusión de estudiantes con discapacidad auditiva en el aula regular. Es un estudio de caso en el que los principales datos se obtuvieron de los maestros de la institución. El estudio propuesto se realizó en cuatro campos del IFES. Los resultados indicaron la necesidad de llevar a cabo un plan educativo dirigido a la formación de maestros, lo que implica al individuo, la familia, los maestros y la institución. Al realizar una retroalimentación en forma de informe a los entrevistados y gerentes de los campus, los resultados obtenidos fueron considerados satisfactorios, alcanzando asi los objetivos propuestos. Además, este trabajo debe contribuir a la construcción del conocimiento en cuanto a la inclusión de las personas con discapacidad auditiva. Los resultados pueden ser adaptados a la realidad de las diferentes situaciones, regiones y localidades que identifiquen la necesidad de formación de los maestros, teniendo como visión la inclusión de estudiantes con discapacidad auditiva, respetando los principios de los pilares éticos, sociales y normativos de cada realidad. Es necesario que la escuela encuentre alternativas prácticas, construidas y dialogadas para incluir de manera efectiva.

Palabras clave: La inclusión escolar. La formación del profesorado y la formación. La discapacidad auditiva. 


\section{REFERÊNCIAS}

ALARCÃO, I. Professores reflexivos em uma escola reflexiva. São Paulo: Cortez, 2010. (Questões da nossa época, 8).

ALBERTI, T. F. et al. Dinâmicas de grupo orientadas pelas atividades de estudo: desenvolvimento de habilidades e competências na educação profissional. Revista Brasileira de Estudos Pedagógicos, v. 95, n. 240, p. 346-62, maio/ago.2014. doi:10.1590/S2176-66812014000200006

ALMEIDA, J. P.; ROCHA, I. S.; PEIXOTO, S. A. Uma reflexão acerca do ensino de geografia e da inclusão de alunos surdos em classes regulares. Revista Brasileira de Educação em Geografia, v. 3, n. 5, p. 98-118, jan./jun. 2013.

ALVES, A. J. O planejamento de pesquisas qualitativas em educação. Cadernos de Pesquisa, n. 77, p. 53-61, maio 1991.

ANDRÉ, M. O que é um estudo de caso qualitativo em educação? Revista da FAEEBA-Educação e Contemporaneidade, v. 22, n. 40, p. 95-103, jul./dez. 2013.

AZAMBUJA, G.; SOUZA, C. R. S.; PAVÃO, S. M. O. Cultura de educação inclusiva: a educação especial e os processos formativos de professores. Revista Reflexão e Ação, v. 20, n. 2, p. 291-308, jun./dez. 2012. doi:10.17058/rea.v20i2.2770

BEHAR, P. A.; TORREZZAN, C. A. W. Educação por competências e experiência estética: planejando a interatividade homem-máquina de materiais educacionais digitais. Revista Iberoamericana de Tecnologia en Educación y Educación en Tecnología, n. 13, p. 8-17, jun. 2014.

BRASIL. Decreto ${ }^{0} 3.298$, de 20 de dezembro de 1999. Regulamenta a Lei no 7.853, de 24 de outubro de 1989, dispõe sobre a Política Nacional para a Integração da Pessoa Portadora de Deficiência, consolida as normas de proteção, e dá outras providências. Diário Oficial da União, 21 dez. 1999. Seção 1, p. 10.

. Decreto $\mathrm{n}^{\circ} 5.296$, de 2 de dezembro de 2004. Regulamenta as Leis nos 10.048 , de 8 de novembro de 2000 , que dá prioridade de atendimento às pessoas que especifica, e 10.098, de 19 de dezembro de 2000, que estabelece normas gerais e critérios básicos para a promoção da acessibilidade das pessoas portadoras de deficiência ou com mobilidade reduzida, e dá outras providências. Diário Oficial da União, 25 abr. 2002. Seção 1, p. 23. 
BRASIL. Decreto $n^{\circ} 6.571$, de 17 de setembro de 2008. Dispõe sobre o atendimento educacional especializado, regulamenta o parágrafo único do art. 60 da Lei $n^{\circ}$ 9.394, de 20 de dezembro de 1996, e acrescenta dispositivo ao Decreto $^{\circ}$ 6.253, de 13 de novembro de 2007. Diário Oficial da União, 18 set. 2008a. Seção 1, p. 26.

. Lei $\mathrm{n}^{\circ} 4.024$, de 20 de dezembro de 1961. Fixa as diretrizes e bases da educação nacional. Diário Oficial da União, 27 dez. 1961, Seção 1, p. 11429.

. Lei $\mathrm{n}^{\circ} 8.069$, de 13 de julho de 1990. Dispõe sobre o Estatuto da Criança e do Adolescente e dá outras providências. Diário Oficial da União, 16 jul. 1990, Seção 1, p. 13563.

. Lei $\mathrm{n}^{\circ} 9.394$, de 20 de dezembro de 1996. Estabelece as diretrizes e bases da educação nacional. Diário Oficial da União, 23 dez. 1996. Seção 1, p. 27833.

. Lei $\mathrm{n}^{\circ} 10.436$, de 24 de abril de 2002. Dispõe sobre a Língua

Brasileira de Sinais - Libras e dá outras providências. Diário Oficial da União, 25 abr. 2002. Seção 1, p. 23.

. Lei $\mathrm{n}^{\circ} 12.796$, de 4 de abril de 2013. Altera a Lei $\mathrm{n}^{\circ}$ 9.394, de 20 de dezembro de 1996, que estabelece as diretrizes e bases da educação nacional, para dispor sobre a formação dos profissionais da educação e dar outras providências. Diário Oficial da União, 5 abr. 2013. Seção 1, p. 1.

. Ministério da Educação. Politica nacional de educação especial na perspectiva da educação inclusiva: documento elaborado pelo Grupo de Trabalho nomeado pela Portaria $\mathrm{n}^{\circ} 555 / 2007$, prorrogada pela Portaria n 9 948/2007, entregue ao Ministro da Educação em 07 de janeiro de 2008. Brasília, DF, 2008b. Disponível em: <http://portal.mec.gov.br/arquivos/pdf/ politicaeducespecial.pdf $>$. Acesso em: 12 fev. 2016.

. Ministério da Educação. Subsídios para organização e funcionamento de serviços de educação especial: área de deficiência mental. Brasília, DF, 1995. Disponível em: <http://www.dominiopublico.gov.br/download/texto/ me002898.pdf>. Acesso em: 11 fev. 2016.

. Senado Federal. Constituição da República Federativa do Brasil. Brasília, DF: Senado Federal, 1988. 
CAMPOS, M. B.; SILVEIRA, M. S.; SANTAROSA, L. M. C. Tecnologias para educação especial. Informática na Educação: Teoria \& Prática, v. 2, n. 1, p. 55-72, maio 1999.

CARVALHO, O. F.; SOUZA, F. H. M. Formação do docente da educação profissional e tecnológica no Brasil: Um diálogo com as faculdades de educação e o curso de pedagogia. Educação \& Sociedade, v. 35, n. 128, p. 883-907, jul.-set. 2014. doi:10.1590/ES0101-73302014124974

COOK, J. A.; BURKE, J. Public policy and employment of people with disabilities: Exploring new paradigms. Behavioral Sciences and the Law, v. 20, n. 6, p. 541-57, 2002. doi:10.1002/bsl.515

COSTA, A. et al. A Inclusão de pessoas com deficiência no mercado de trabalho: um estudo de caso. In: SIMPÓSIO CIENTÍFICO DE GRADUAÇÃO E PÓS-GRADUAÇÃO, 2013, Bento Gonçalves. Anais... Bento Gonçalves: FTSG, 2013. p. 1-16.

COSTA, V. A. Experiências pela educação: para quê? Formação e inclusão na perspectiva da teoria crítica. Revista Educação Especial, v. 26, n. 46, p. 245-60, maio/ago. 2013. doi:10.5902/1984686X8029

DIAS, I. S. Competências em educação: conceito e significado pedagógico. Psicologia Escolar e Educacional, v. 14, n. 1, p. 73-8, jan./jun. 2010. doi:10.1590/S1413-85572010000100008

FAGLIARI, S. S. S. A educação especial na perspectiva da educação inclusiva: ajustes e tensões entre a política federal e a municipal. 2012. 267 f. Dissertação (Mestrado em Educação) — Faculdade de Educação, Universidade de São Paulo, 2012.

FRANÇA, I. S. X.; PAGLIUCA, L. M. F.; BAPTISTA, R. S. Política de inclusão do portador de deficiência: possibilidades e limites. Acta Paulista de Enfermagem, v. 21, n. 1, p. 112-6, jan./mar. 2008. doi:10.1590/S0103-21002008000100018

HOLZHEIM, D. C. P. M. et al. Família e fonoaudiologia: o aprendizado da escuta. In: LOPES FILHO, O. C. (Ed.). Tratado de fonoaudiologia. São Paulo: Roca, 1997.

IBGE - Instituto Brasileiro de Geografia e Estatística. Censo 2010. Disponível em: <http://censo2010.ibge.gov.br/>. Acesso em: 12 fev. 2016. 
IFES - Instituto Federal do Espírito Santo. Institucional. 2014. Disponível em: $<$ http://www.ifes.edu.br/campi $>$. Acesso em: 12 fev. 2016.

KUNZE, N. C. O surgimento da rede federal de educação nos primórdios do regime republicano no Brasil. Revista Brasileira de Educação Profissional e Tecnológica, v. 2, n. 2, p. 8-24, 2009. doi:10.15628/rbept.2009.2939

LAMICHHANE, K.; SAWADA, Y. Disability and returns to education in a developing country. Economics of Education Review, v. 37, p. 85-94, 2013. doi:10.1016/j.econedurev.2013.08.007

LIMA, M. C. B.; CASTRO, G. F. Formação inicial de professores de física: a questão da inclusão de alunos com deficiências visuais no ensino regular. Ciência \& Educação (Bauru), v. 18, n. 1, p. 81-98, 2012. doi:10.1590/S1516-73132012000100006

MARIN, A. J.; ZEPPONE, R. M. O. O trabalho docente e a inclusão escolar: impactos e mudanças em sala de aula. Olhar de Professor, v. 15, n. 1, p. 139-49, 2012. doi:10.5212/OlharProfr

MAZZOTTA, M. J. S.; D'ANTINO, M. E. F. Inclusão social de pessoas com deficiências e necessidades especiais: cultura, educação e lazer. Saúde e Sociedade, v. 20, n. 2, p. 377-89, abr.jun. 2011. doi:10.1590/S0104-12902011000200010

MENDES, G. M. L.; OLIVEIRA, E. A. S.; NAZÁRIO, D. C. Cultura escolar e inovação curricular em escolas inclusivas. In: CONGRESSO INTERNACIONAL DE EDUCAÇÃO UNIBAVE, 3., 2008, Orleans. Anais... Orleans: Unibave, 2008. p. 3-12.

MICHELS, M. H. O que há de novo na formação de professores para a Educação Especial? Revista de Educação Especial, v. 24, n. 40, p. 219-32, maio/ago. 2011. doi:10.5902/1984686X2668.

MIOTTO, A. C. F. As práticas curriculares no contexto da sala de aula inclusiva: avanços e impasses na inclusão dos educandos com deficiência visual. Revista Eletrônica de Educação, v. 4, n. 1, p. 34-49, maio 2010.

NAUJORKS, M. I. Stress e inclusão: indicadores de stress em professores frente à inclusão de alunos com necessidades educacionais especiais. Educação Especial, n. 20, p. 117-25, 2002. doi:10.5902/1984686X 
PEREIRA, F. K. Pedagogia das competências na educação profissional: contribuições da formação continuada para saberes e competência docente. E-Tech: Tecnologias para Competitividade Industrial, n. Esp. Educação, p. 31-52, 2013. doi:10.18624/e-tech.v0i0.393

PERRENOUD, P. 10 novas competências para ensinar: convite à viagem. Porto Alegre: Artmed, 2000. (Biblioteca Armed).

PIATTO, V. B.; MANIGLIA, J. V. Avaliação da audição e crianças de 3 a 6 anos em creches e pré-escolas municipais. Jornal de Pediatria (Rio Janeiro), v. 77, n. 2, p. 124-30, abr./maio 2001. doi:10.1590/S0021-75572001000200013

RODRIGUES, D. Desenvolver a educação inclusiva: dimensões do desenvolvimento profissional. Inclusão: Revista da Educação Especial, v. 4, n. 2, p. 7-16, jul./out. 2008.

RODRIGUES, D.; LIMA-RODRIGUES, L. Formação de professores e inclusão: como se reformam os reformadores? Educar em Revista, n. 41, p. 41-60, jul./set. 2011. doi:10.1590/S0104-40602011000300004

SALA, E. A formação de professores especializados no ensino de portadores de deficiência visual: aspectos básicos. Ensino em Revista, v. 2, n. 1, p. 57-67, jan./dez. 1993.

SANTOS, A. C.; PEREIRA, E. S.; LIMA, V. C. Práticas da educação inclusiva na escola e suas dificuldades. Revista Brasileira de Educação e Saúde, v. 4, n. 1, p. 36-40, jan./mar. 2014.

SANTOS, M. P. Ressignificando a formação de professores para uma educação inclusiva: relatório final. Rio de Janeiro: Laboratório de Pesquisa, Estudos e Apoio à Participação e à Diversidade em Educação - LAEADE, 2007.

SASSAKI, R. K. Vida Independente: história, movimento, liderança, conceito, filosofia e fundamentos. São Paulo: RNR, 2003.

SENO, M. P. A inclusão do aluno com perda auditiva na rede municipal de ensino da cidade de Marília. Revista Psicopedagogia, v. 26, n. 81, p. 376-87, 2009.

SIEMS, M. E. R. A construção da identidade profissional do professor da educação especial em tempos de educação inclusiva. 2008. 179 f. Dissertação (Mestrado em Educação) - Universidade Federal de Juiz de Fora, Programa de Pós-graduação em Educação, Juiz de Fora, 2008. 
SILVA, C. N. N.; ARAÚJO, J. S. A inclusão de alunos surdos: demarcações políticas, conquistas e intervenção pedagógica. Outras Palavras, v. 8, n. 2, p. 12-28, 2012.

SILVA, M. K. C. L.; FÉLIX, R. R.; JORGE, F. V. A inclusão do surdo no ensino regular. Nativa: Revista de Ciências Sociais do Norte de Mato Grosso, v. 1, n. 2, p. 1-9, 2014.

SILVA, M. O. E. Dados de investigação em ciências da educação e em artes visuais: testemunho para a construção da escola inclusiva. Revista Lusófona de Educação, n. 25, p. 177-92, 2013.

SMEHA, L. N.; FERREIRA, I. V. Prazer e sofrimento docente nos processos de inclusão escolar. Revista Educação Especial, v. 1, n. 31, p. 37-48, 2008. doi:10.5902/1984686X

THOMA, A. S.; KLEIN, M. Experiências educacionais, movimentos e lutas surdas como condições de possibilidade para uma educação de surdos no Brasil. Cadernos de Educação, n. 36, p. 107-31, maio/ago. 2010.

TREVISAN, J. G.; DELLABARBA, P. C. S. Reflexões acerca da atuação do terapeuta ocupacional no processo de inclusão escolar de crianças com necessidades educacionais especiais. Cadernos de Terapia Ocupacional da UFSCar, v. 20, n. 1, p. 89-94, 2012. doi:10.4322/cto.2012.010

UNESCO - United Nations Educational, Scientific and Cultural Organization. Declaração de Salamanca. In: Conferência Mundial de Educação Especial, 1994, Salamanca. Proceedings... Salamanca: Unesco Press, 1994. p. 10.

WHO - World Health Organization. Prevention of deafness and hearing impairment. Geneva; 2014. Disponível em: <http://www.who.int/pbd/ deafness>. Acesso em: 12 de fev. 2016.

XAVIER, A. N.; BARBOSA, P. Com quantas mãos se faz um sinal? Um estudo do parâmetro número de mãos na produção de sinais da língua brasileira de sinais (libras). Todas as Letras-Revista de Lingua e Literatura, v. 15, n. 1, p. 111-28, 2013.

YIN, R. K. Estudo de caso: planejamento e métodos. 5. ed. Porto Alegre: Bookman, 2015. 


\section{Informações dos autores}

Wellington Gonçalves: Doutorando em Engenharia de Produção, Universidade Metodista de Piracicaba - UNIMEP. Professor Adjunto I, Coordenador do Laboratório de Pesquisa Operacional e Logística, Universidade Federal do Espírito - UFES. Contato: wellington. goncalves@ufes.br

Verana Maria Fornaciari Gonçalves: Mestre em Gestão Social, Educação e Desenvolvimento Regional, Faculdade Vale do Cricaré - FVC. Coordenadora de Gestão de Pessoas, Instituto Federal de Educação, Ciência e Tecnologia do Espírito Santo - IFES. Contato: vgoncalves@ifes.edu.br

Lilian Pittol Firme: Doutorado em Agronomia - USP. Professor do Ensino Superior, Mestrado em Gestão Social, Educação e Desenvolvimento Regional, Faculdade Vale do Cricaré - FVC. Contato: lpfirme@gmail.com 